\title{
LA METÁFORA DE LA CONFRONTACIÓN Y LOS ARGUMENTADORES RAZONABLES
}

\author{
José ÁNGEL GASCÓN \\ Universidad Católica del Maule \\ Departamento de Filosofía \\ jgascon@ucm.cl
}

RESUMEN: Las discusiones argumentativas comúnmente se describen en términos confrontativos, pero no está claro que la argumentación sea necesariamente confrontativa. Aquí argumento que la confrontación no es un elemento esencial de la argumentación y de hecho debe evitarse porque desalienta el comportamiento razonable. La razonabilidad, caracterizada aquí como una disposición a modificar las creencias propias ante buenos argumentos, es puesta en peligro por las metas confrontativas. Eso nos da una razón para rechazar la confrontación en la argumentación, pues la razonabilidad contribuye a algunos de los mayores bienes que la argumentación puede producir.

PALABRAS CLAVE: argumentación, creencia, desacuerdo, metáforas, razonabilidad

SUMMARY: Argumentative discussions are commonly described in adversarial terms, but it is not obvious that argumentation is necessarily adversarial. Here I argue that adversariality is not an essential element in argumentation and in fact it must be avoided because it discourages reasonable behaviour. Reasonableness, characterised here as willingness to modify one's own beliefs in the light of good arguments, is jeopardised by adversarial goals. That gives us a reason to reject adversariality in argumentation, since reasonableness contributes to some of the greatest goods that argumentation can provide.

KEY WORDS: argumentation, belief, disagreement, metaphors, reasonableness

\section{Introducción}

Es común distinguir entre los argumentos como productos de la actividad de argumentar y la argumentación como proceso (O'Keefe 1977). Los argumentos pueden entenderse como conjuntos de enunciados tales que unos (llamados "premisas" o "razones") proporcionan un apoyo a otro (llamado "conclusión" o "tesis"). La argumentación, entendida como un proceso, es la actividad en la que los argumentadores intercambian argumentos. Típicamente se postula $-\mathrm{o}$ se asume implícitamente - que tales intercambios de argumentos 
surgen a raíz de un desacuerdo ${ }^{1}$ entre dos o más personas (Eemeren 2018). Sin embargo, es evidente - aunque no siempre se tenga en cuenta - que la argumentación involucra mucho más que simples intercambios de argumentos. La argumentación, como toda interacción humana, involucra multitud de comportamientos y actitudes.

Durante las últimas décadas ha surgido un creciente interés en un aspecto de la práctica argumentativa que siempre ha estado ahí pero no formaba parte de las preocupaciones de los teóricos de la argumentación: el carácter confrontativo de la argumentación. Las discusiones argumentativas habitualmente se describen en términos de una competición entre oponentes - o incluso en términos bélicos- Esto ha suscitado varias críticas, pero el paradigma de la confrontación también ha sido defendido por algunos teóricos. Mi propósito en este artículo es argumentar que la práctica argumentativa no tiene por qué verse como una confrontación, y de hecho es preferible no hacerlo.

Comenzaré por presentar un bosquejo de esta discusión en la sección 2. Después, en la sección 3, trataré de arrojar algo de claridad sobre qué se entiende por "confrontativo" y argumentaré que la argumentación no es una actividad esencialmente confrontativa -al menos en un sentido significativo e interesante del término "confrontativo"-. Por lo tanto, el uso de términos confrontativos para describir la argumentación es una opción, una decisión que debemos tomar. En la sección 4 ofreceré mi principal razón para no caracterizar las discusiones como confrontaciones: de acuerdo con una concepción bastante natural de la razonabilidad, los objetivos de la argumentación como una actividad confrontativa entran en conflicto con la actitud que se espera de unos argumentadores razonables. Así que debemos elegir entre la confrontación y la razonabilidad. Finalmente, en la sección 5 expondré algunas consideraciones que sugieren que un comportamiento razonable arroja los mejores resultados en la argumentación, y por tanto la razonabilidad debe fomentarse —en detrimento de la confrontación-.

\section{La cuestión de la confrontación}

En su trabajo sobre las metáforas, Lakoff y Johnson (1980) sostuvieron que las metáforas no son meros recursos estilísticos sino el fundamento de nuestros sistemas conceptuales, que nos orientan a la

\footnotetext{
${ }^{1}$ Presentar una definición precisa de "desacuerdo" excedería la complejidad y los propósitos del presente artículo. Para lo que aquí nos interesa, el desacuerdo puede caracterizarse como una situación en la que se ha puesto de manifiesto que dos personas tienen creencias incompatibles.
} 
hora de pensar y actuar. El pensamiento humano, según estos autores, es inherentemente metafórico: comprendemos y experimentamos algunas cosas en términos de otras. El primer ejemplo que Lakoff y Johnson ofrecieron es la metáfora de la argumentación como la guerra, que vieron reflejada en varias expresiones que comúnmente utilizamos en contextos argumentativos (p. 4): las afirmaciones son indefendibles, los argumentadores atacan los puntos débiles de los argumentos, las discusiones se ganan, los argumentos son destrozados... Estas expresiones, sostuvieron los autores, no son simplemente una manera de hablar sobre la argumentación; son realmente la manera en la que pensamos sobre la argumentación:

Es importante ver que no solo hablamos sobre las discusiones en términos de una guerra. Realmente podemos ganar o perder discusiones. Vemos a la persona con la que estamos argumentando como un oponente. Atacamos sus posiciones y defendemos las nuestras. Ganamos y perdemos terreno. Planeamos y usamos estrategias. Si una posición nos parece indefendible, podemos abandonarla y emprender una nueva vía de ataque. Muchas de las cosas que hacemos al argumentar están estructuradas parcialmente por el concepto de la guerra. Aunque no haya una batalla física, hay una batalla verbal, y la estructura de una discusión - ataque, defensa, contraataque, etc.- refleja esto. En este sentido la metáfora de la argumentación como una guerra es una según la cual vivimos en esta cultura; ella estructura las acciones que realizamos al argumentar. (p. 4) $)^{2}$

Sin embargo, el texto que desencadenó la actual discusión sobre la confrontación en la argumentación fue el famoso artículo de Moulton (1983) en el que criticaba una manera de hacer filosofía que ella llamó "Paradigma de la confrontación" (Adversary Paradigm). ${ }^{3}$ Moulton identificó este paradigma — en el sentido de Thomas Kuhn - que, según sostuvo, era dominante en filosofía:

Bajo el Paradigma de la confrontación se asume que la única o, en todo caso, la mejor manera de evaluar un trabajo en filosofía es someterlo a la oposición más fuerte o extrema. Y se asume que la mejor manera de presentar un trabajo en filosofía es dirigirse a un oponente imaginario y reunir todas las pruebas que uno pueda para apoyar su propia postura. (p. 153)

${ }^{2}$ Aquí y en adelante, las traducciones de los textos en inglés son mías.

${ }^{3}$ En todo el artículo, he traducido "adversariality" como "confrontación". Aunque no estoy satisfecho con el término, no encontré otro mejor. 
Tal forma de hacer filosofía, según Moulton, “acepta una visión positiva del comportamiento agresivo y la usa como el paradigma del razonamiento filosófico" (p. 149). Se necesitan, argumentó esta autora, paradigmas alternativos para la práctica filosófica, ya que "es poco probable que las condiciones de hostilidad produzcan el mejor razonamiento" (p. 153).

Aunque Moulton estaba preocupada por la práctica filosófica en general, sus críticas eran obviamente pertinentes para la teoría de la argumentación en concreto. Por ello, algunos teóricos de la argumentación siguieron sus pasos. Cohen (1995, p. 182) se refirió a las metáforas bélicas en la argumentación cuando habló sobre "una ideología de la argumentación que casi no ha sido examinada y que tiene que ser sometida a su propio escrutinio argumentativo". Sostuvo que es posible servirse de otras metáforas en la argumentación, de tal modo que pareció sugerir que la argumentación no es esencialmente confrontativa y puede compararse con otras actividades más colaborativas. De hecho, según Cohen, sería beneficioso usar otras metáforas, ya que la metáfora de la argumentación como una guerra requiere que hablemos sobre "ganadores y perdedores", y eso puede implicar el fomento de una actitud argumentativa poco apropiada: "Hay un mensaje claro aquí y no es el que se declara oficialmente: la lucidez y la comprensión están bien, desde luego, pero, si uno quiere salir adelante, la astucia y la destreza retórica son lo que realmente importa en la vida" (p. 180).

Así que una de las preocupaciones sobre la representación de la argumentación en términos confrontativos es que eso fomenta que los argumentadores se comporten de manera indeseable. Una crítica diferente de este paradigma, sin embargo, no tiene que ver con las consecuencias de la metáfora bélica sino con la inexactitud con la que ese paradigma describe lo que sucede cuando las personas argumentan. Rooney es una de las autoras que presenta esta crítica:

[D]ebemos examinar cuidadosamente el paso desde la diferencia y el desacuerdo hasta la oposición y la confrontación, no simplemente porque estas últimas puedan resultar incómodas para algunos argumentadores, sino porque ese paso malinterpreta el papel epistémico de las buenas discusiones como importantes herramientas de persuasión racional en la adquisición y la comunicación de verdades o verdades probables. (2010, p. 211)

Rooney sostiene que las metáforas competitivas y bélicas en la argumentación hacen que el paso del desacuerdo a la confrontación 
sea demasiado fácil de dar, pero ese paso no está justificado. Si, por ejemplo, tú y yo estamos argumentando y yo termino por estar de acuerdo contigo, decir que yo he "perdido" la discusión y tú has "ganado" es una mala interpretación de lo que ha ocurrido realmente:

Pero sin duda soy yo quien ha obtenido una ganancia epistémica, por pequeña que sea. He sustituido una creencia probablemente falsa por una probablemente verdadera, y tú no has obtenido tal ganancia (aunque, por supuesto, puedes reclamar cierto éxito y satisfacción al haberme ayudado con mi ganancia epistémica). (p. 222)

Además, según Rooney, decir que hay un "conflicto" entre dos personas que están en desacuerdo no es una representación adecuada de lo que está pasando realmente. Ya tenemos "términos epistémicos o lógicos perfectamente válidos, tales como 'contradictorio' o 'inconsistente', que describen de manera mucho más precisa cuál es el "conflicto"" (p. 222).

En resumen, dos son las principales razones que se han presentado para rechazar el uso de términos confrontativos en la argumentación: (1) los términos confrontativos fomentan un comportamiento indeseable, y (2) los términos confrontativos tergiversan la práctica argumentativa. Sin embargo, estas razones han sido discutidas. Varios teóricos han presentado fuertes argumentos que apoyan la idea de que la argumentación es, por su propia naturaleza, al menos mínimamente confrontativa. Pasemos ahora a ver el otro lado de esta disputa.

Govier (1999) ha distinguido entre dos tipos de confrontación en la argumentación: la confrontación mínima (minimal adversariality), que tiene lugar simplemente debido al hecho de que los argumentadores sostienen puntos de vista opuestos, y la confrontación adicional (ancillary adversariality), caracterizada por la agresión y la hostilidad. La confrontación adicional implica "falta de respeto, rudeza, falta de empatía, insultos, animosidad, hostilidad, ausencia de una escucha y una atención cuidadosas, tergiversación, ineficacia, dogmatismo, intolerancia, irritabilidad, belicosidad, etc." (p. 245), y por tanto debe evitarse. ${ }^{4}$ No obstante, Govier también sostiene que un nivel

${ }^{4}$ Este tipo de confrontación adicional puede equipararse a las actitudes que Brockriede (1972) caracterizó como "violación" y "seducción”. El artículo de Brockriede "Arguers as Lovers" es una defensa de una actitud cooperativa en la argumentación. En sus palabras: "Mientras que el violador y el seductor argumentan contra un adversario o un oponente, el amante argumenta con sus iguales y está dispuesto a arriesgar su propio ser en su intento por establecer una relación bilateral" (p. 5). Todos los autores mencionados en el presente artículo estarían de 
mínimo de confrontación no solo carece de todas esas implicaciones negativas sino que de hecho puede ser intrínseco a la argumentación. Ella presenta su argumento de la siguiente forma (p. 244):

1. Sostengo X.

2. Creo que X es correcto. (Se sigue de (1).)

3. Creo que no-X no es correcto. (Se sigue de (2).)

4. Creo que quienes sostienen no-X están equivocados o están cometiendo un error. (Se sigue de (3).)

5. Si tuviera que argumentar a favor de X, estaría por ello argumentando en contra de no-X. (?)

6. Quienes sostienen no-X son, respecto a la corrección de $\mathrm{X}$ y de mi argumento a favor de $\mathrm{X}$, mis oponentes. (?)

Govier admite que los pasos 4-5 y 5-6 son "cuestionables". No obstante, ella sostiene que, cuando argumentamos a favor de una afirmación, al mismo tiempo estamos necesariamente argumentando contra quien no acepte ese afirmación. Y esa oposición es precisamente la esencia de la confrontación, según la caracterización que ella proporciona: decir que una práctica es confrontativa "significa que en esa práctica las personas desempeñan papeles que sitúan a unas contra otras, como adversarias u oponentes" (p. 242). Por lo tanto, concluye, si consideramos la confrontación mínima, entonces "la argumentación es confrontativa en sus mismas raíces" (p. 243). Sin embargo, añade Govier, no hay ninguna razón para que este nivel mínimo de confrontación nos impida mantener al margen los elementos adicionales de confrontación.

La tesis de que la argumentación es confrontativa, al menos en un sentido mínimo, también ha sido defendida por Aikin (2011) y Casey (2020). Aikin reconoce el valor que tienen las metáforas no bélicas para la argumentación, pero insiste en que son simplemente formas de mitigar la confrontación intrínseca a las discusiones. Siguiendo a Govier, sostiene que la argumentación es esencialmente confrontativa debido al hecho de que, cuando alguien argumenta con una persona, está en desacuerdo con ella y cree que ella está equivocada. Casey también coincide con Govier en que la argumentación

acuerdo con Brockriede en que las actitudes de "violación" y de "seducción" son censurables, pues involucran ese exceso de confrontación que, según Govier, debe evitarse. Agradezco a un revisor anónimo que llamara mi atención sobre este punto. 
tiene un carácter esencialmente confrontativo, pero proporciona una caracterización más detallada de en qué consiste una confrontación. Sorprendentemente, Casey no considera que el desacuerdo sea una condición necesaria para la confrontación, pues dice:

Un adversario puede ser, después de todo, un amigo que va en contra de tus intereses. Él está de acuerdo contigo y tú con él, pero ese acuerdo es malo. Peor aún, este "amigo" puede, a causa de vuestra amistad, usar tipos colaborativos o (supuestamente) no confrontativos de argumentos que van encaminados al consenso para conseguir sus propósitos confrontativos. (p. 84)

También señala que la confrontación no implica agresividad, así que las preocupaciones sobre los comportamientos innecesariamente agresivos en la argumentación no deberían llevarnos a rechazar su carácter intrínsecamente confrontativo (p. 91). Para poder explicar qué tiene la argumentación de específicamente confrontativo, Casey hace una distinción entre dos tipos de confrontación:

Confrontación de intereses (adversariality of interest): los participantes en este tipo de actividad confrontativa compiten por algo que no pueden tener ambos. Tienen "intereses opuestos o inconsistentes" (p. 86). Aquí puede decirse apropiadamente que un participante gana mientras que el otro pierde. Este es el tipo de confrontación que caracteriza a ámbitos como el derecho, los negocios, los juegos o la guerra.

Interacción confrontativa (adversariality of interaction): una actividad confrontativa en este sentido no requiere una competición sobre algún bien, sino que es una en la que los participantes interactúan como adversarios. Eso significa que: "si dos personas, $A$ y $B$, interactúan como adversarios, entonces las acciones de $A$ sobre $B$ y de $B$ sobre $A$, para los propósitos y la duración del intercambio confrontativo, se caracterizan por la involuntariedad; $A$ intentará imponer un resultado a $B$ o frustrar los intentos de $B$ de hacer lo mismo a $A$ " (p. 87). Ejemplos de interacciones confrontativas son las luchas y otras aplicaciones de fuerza física.

La argumentación, concluye Casey, es esencialmente confrontativa en el segundo sentido: es una interacción esencialmente confrontativa. Él presenta dos razones principales para esa conclusión. En primer lugar, las discusiones son intentos por parte de un argumentador de 
cambiar las creencias de otras personas, y las creencias no pueden ser creadas y abandonadas a voluntad por el creyente - es decir, las creencias son involuntarias - . Por lo tanto, argumenta Casey, en una discusión los argumentadores intentan imponer una creencia a otros, los argumentos implican imposiciones involuntarias: "Compartir razones contigo es la forma en la que la imposición se practica en las discusiones" (p. 98). En segundo lugar, la argumentación es una interacción confrontativa porque "participar en una discusión puede ser una actividad arriesgada y potencialmente costosa" (p. 102). Es posible que uno descubra debilidades en su posición, el desacuerdo puede exacerbarse, los participantes pueden sufrir un daño emocional y la alteración resultante de su sistema de creencias puede tener costes epistémicos y sociales.

En varios puntos de su artículo, Casey deja claro que la principal razón por la que la argumentación es una interacción confrontativa es la involuntariedad de la creencia. Así, por ejemplo, dice:

La característica central de cualquier práctica esencial y naturalmente confrontativa es la involuntariedad. Esto involucra a la argumentación debido a la involuntariedad de la creencia. La argumentación, en la medida en que esté centrada en creencias, es esencialmente confrontativa porque interactuar con las creencias de alguien es intentar forzarlo. (pp. 100-101)

Como puede verse, se han ofrecido fuertes argumentos que parecen mostrar que la argumentación es una actividad intrínsecamente confrontativa. Si tal es el caso, entonces no tiene mucho sentido insistir en que no debería describirse en términos confrontativos - simplemente es así-. Así que, antes de entrar en la cuestión de los perjuicios que puede causar el vocabulario confrontativo, es importante solucionar ese punto. Esa es la tarea de la próxima sección.

\section{3. ¿Es la argumentación esencialmente confrontativa?}

Como hemos visto, el argumento principal de Govier para sostener que la argumentación es esencialmente confrontativa se apoya en la idea de que argumentar a favor de X implica argumentar en contra de no-X (paso 5), y argumentar en contra de no-X implica que quienes sostengan no-X son mis oponentes (paso 6). Aunque Govier comenta que ambos pasos son cuestionables, lo cierto es que el paso 5 me resulta muy razonable: no requiere más apoyo que el principio de no contradicción. El paso 6, no obstante, es bastante más problemático: 
implica pasar de una consideración epistémica (la falsedad de no-X) a una consideración dialéctica (la caracterización de quien sostiene no-X como un "oponente"). ${ }^{5}$ Ese paso es precisamente lo que está en discusión aquí, pero lamentablemente Govier no proporciona ninguna razón que lo sustente. Simplemente asume que el desacuerdo implica necesariamente una confrontación —algo de lo que yo no estoy convencido-.

El argumento de Casey, en cambio, tiene el mérito de ser mucho más explícito sobre qué es lo que hace que la argumentación sea confrontativa y por esta razón me centraré en él. Sin embargo, creo que hay un paso implícito en ese argumento que no es evidente. Como hemos visto, la involuntariedad de la creencia es la principal razón de Casey para sostener su tesis de que la argumentación es una interacción confrontativa. Pero, para pasar de esa razón a esa tesis, es necesario un paso intermedio que él simplemente asume: alterar algo sobre lo que una persona no tiene control directo implica imponerle algo a esa persona. Creo, sin embargo, que es muy poco plausible que la involuntariedad equivalga a una imposición en todos los casos.

Veamos un ejemplo simple de involuntariedad. Supongamos que un trozo de comida ha obstruido mis vías respiratorias y me estoy asfixiando. Yo he intentado, sin éxito, eliminar esa obstrucción tosiendo - es decir, he sido incapaz de eliminarla voluntariamenteAsí que necesito algo de ayuda. Entonces un transeúnte se acerca a mí y me aplica la maniobra de Heimlich, y como resultado el trozo de comida es expulsado y puedo respirar de nuevo. Este es, en mi opinión, un caso claro de involuntariedad: otra persona hace en mí algo que yo mismo no puedo hacer porque no está bajo mi control. Sin embargo, tiene poco sentido decir que la persona que salvó mi vida era mi adversaria. La razón de ello es que esa persona no forzó en mí algo que yo no tenía la disposición de hacer. Puede decirse lo mismo de las operaciones quirúrgicas en general $-\mathrm{y}$, por cierto, nótese que tales operaciones también son indudablemente costosas, no solo porque sean caras sino porque provocan dolor y posibles complicaciones-. El elemento de la involuntariedad está presente, pero los cirujanos no son adversarios; me están ayudando.

Las cosas se ponen aún más difíciles para Casey debido al hecho de que él no considera que el desacuerdo sea una condición necesaria para la confrontación - la involuntariedad de la creencia, según él, es suficiente - Si he comprendido bien sus argumentos, eso nos lleva

${ }^{5}$ Debo dar las gracias a Mario Gensollen por señalar este punto. 
a una conclusión inaceptable: cualquier cambio de creencias provocado por otra persona debería ser considerado como una interacción confrontativa. Eso incluye, por ejemplo, lo que sucede cuando estoy perdido en una ciudad y pregunto a alguien cómo llegar a mi destino; al darme indicaciones, la otra persona está modificando mis creencias - ha creado en mí una que yo no tenía-. Parece evidente que ese breve diálogo ha sido una actividad colaborativa. Sin embargo, según el criterio de Casey, debería considerar a la persona que me ha ayudado como un adversario.

Por lo tanto, la involuntariedad de la creencia no parece suficiente para la interacción confrontativa. Cuando una persona provoca en otra un cambio que esta última no puede controlar, eso solo puede verse como una imposición si esta última es reacia a ese cambio. La caracterización que hace Casey de las interacciones confrontativas, así como los ejemplos que proporciona (luchas), no dejan lugar a dudas de que ese elemento de resistencia está presente. Cuando describe la interacción confrontativa, señala que "un adversario es tanto alguien que frustra tus acciones como alguien que te fuerza a hacer algo" (p. 88). Solo cuando alguien trata de forzarme a hacer algo que soy reacio a hacer tiene sentido hablar de frustración e imposición. La involuntariedad, en sí misma, no basta.

Por esta razón, no creo que la distinción entre confrontación de intereses e interacción confrontativa sea una distinción entre dos cosas muy diferentes. Ciertamente, la confrontación de intereses implica una competición por algún bien, mientras que la interacción confrontativa implica intentar imponer la voluntad propia en el otro. Sobre esa base, la distinción tiene algún sentido. No obstante, ambos tipos de confrontación comparten la mayoría de los rasgos que caracterizan una interacción entre oponentes. En concreto, en ambos tipos de confrontación tiene sentido hablar de "ganar" y "perder" - términos que, según Casey, solo son apropiados para la confrontación de intereses (p. 104)- Si, en una interacción confrontativa, ambos participantes intentan imponer un resultado en el otro, parece claro que en cierto sentido quien consiga hacerlo ha "ganado". La gente gana y pierde las luchas y las peleas, incluso aunque no luche por nada en particular.

En conclusión, creo que una actividad confrontativa puede caracterizarse a grandes rasgos como una en la que los participantes actúan como oponentes, intentando imponer su voluntad en el otro o conseguir algún bien que no pueden tener ambos, y cuyo resultado revela que un participante ha sido exitoso (el "ganador") y otro ha 
sido derrotado (el "perdedor"). Creo sinceramente que cualquier otra concepción de la confrontación que incluya menos que eso será una concepción insuficiente.

Así que, para poder caracterizar la argumentación como una práctica confrontativa, es necesario que los participantes intenten imponer sus creencias en interlocutores reacios. ¿Es toda discusión argumentativa siempre una imposición? Sin duda, admito que ciertos (o incluso muchos) contextos argumentativos son confrontativos: como señala Govier, el derecho, la política y los debates institucionales son prácticas en las que los participantes no pueden evitar ser oponentes (1999, p. 242). Sin embargo, eso no nos dice nada sobre si esas prácticas son confrontativas porque son argumentativas. Para mostrar que la argumentación misma es esencialmente confrontativa, en primer lugar debe mostrarse que existe algún tipo de confrontación en todo contexto argumentativo. No creo que ese sea el caso.

He argumentado que la cuestión de si una actividad es confrontativa depende de si los participantes intentan imponer un resultado en otros que son reacios a él. Tal como lo entiendo aquí, la cuestión de qué es lo que uno está dispuesto a aceptar es diferente de la cuestión de qué es lo que uno quiere. Es posible estar dispuesto a aceptar algo sin necesariamente quererlo. Querer implica una preferencia (más o menos fuerte), mientras que la disposición simplemente implica aceptación sin reticencias - lo que también puede incluir la indiferencia-. La relación entre ambas, según creo, es la siguiente: querer $\mathrm{X}$ implica estar dispuesto a aceptar X, y ser reacio a aceptar $\mathrm{X}$ implica querer no-X.

Así que, si la argumentación es confrontativa, eso significa que los argumentadores deben ser reacios a cambiar de opinión. Es decir, deben querer mantener sus actuales creencias. ¿Sucede eso siempre? Sin duda, muchos (probablemente la mayoría) de nosotros, que no somos totalmente virtuosos, queremos que nuestros puntos de vista prevalezcan cuando argumentamos. Sin embargo, no es menos cierto que algunas personas no argumentan desde un interés por que sus creencias prevalezcan. Todos conocemos a alguien cuyo propósito al argumentar es genuinamente epistémico, que desean conocer razones opuestas a las suyas y poner a prueba sus creencias, y que incluso se alegran cuando su sistema de creencias se ve modificado por buenas razones. Tales personas no consideran que ser convencidos con buenos argumentos suponga una "derrota" o una "imposición". Por supuesto, no estoy afirmando que la mayoría de nosotros seamos así, pero si tales personas existen - y creo que es indudable que 
alguna existe-, ellas nos muestran que la argumentación puede no ser confrontativa.

Fijémonos en que eso no significa que quieran cambiar sus creencias. Sin duda ese sería un comportamiento bastante peculiar - todos consideramos que nuestras creencias son verdaderas-. Como ya he dicho, el hecho de que esas personas estén dispuestas a cambiar de opinión no significa que quieran hacerlo. Simplemente significa que, en principio, no tienen una preferencia por sus propias creencias solo por el hecho de que sean suyas. Tienen preferencias, por supuesto, ya que desean tener creencias verdaderas; y se sienten inclinadas hacia sus propias creencias porque suponen que son verdaderas - de lo contrario, no las creerían-. Sin embargo, su deseo de tener creencias verdaderas es indiferente, en principio, a la cuestión de si las creencias que finalmente resultan ser verdaderas son las suyas o las de otro. Tales personas no son reacias a abandonar o modificar sus propias creencias a la luz de buenas razones. Sus intereses son epistémicos.

Se podría pensar, dado que los argumentos de Casey se apoyan en la involuntariedad de la creencia, que todas estas consideraciones sobre "disposición" y "reticencia" no vienen al caso. Después de todo, si no tenemos un control directo sobre nuestras creencias, ¿qué importa que estemos dispuestos a cambiarlas o no? Casey tiene el cuidado de distinguir entre creencias y compromisos: podemos adquirir y retractarnos de compromisos libremente, pero no podemos hacer lo mismo con las creencias. Mis respuestas a esto son que, en primer lugar - como he intentado mostrar - necesitamos la noción de disposición para poder conceptualizar la confrontación; como mostró mi ejemplo de la maniobra de Heimlich, la involuntariedad no es suficiente. Y, en segundo lugar, incluso aunque no podamos controlar directamente nuestras creencias en un momento concreto, podemos seguir procedimientos racionales y cultivar virtudes intelectuales a lo largo del tiempo con el fin de crear las condiciones necesarias para que nuestro sistema de creencias se vea afectado apropiadamente por las razones (Cohen 2019). Eso sí que está bajo nuestro control.

Los casos que mencioné anteriormente de la maniobra de Heimlich y de las operaciones quirúrgicas no eran meros contraejemplos. En cierto sentido, la argumentación puede concebirse de esa manera. Si no tenemos un control directo sobre nuestras creencias, los argumentadores que nos exponen a diferentes puntos de vista y razones nos están ayudando a construir y fortalecer nuestro sistema de creencias. Nos ayudan a hacer algo que no podemos hacer por nosotros mismos. 
Algunas personas lo ven de esa forma y eso se refleja en su comportamiento. En las discusiones en las que tales personas suelen participar, no hay confrontación. Parece, por tanto, que la confrontación no es un rasgo esencial de la argumentación; es simplemente una forma que las discusiones pueden adoptar. Así pues, la pregunta ahora es si se trata de una forma que las discusiones deben adoptar.

\section{Confrontación y razonabilidad}

Recapitulemos: he tratado de mostrar que la argumentación no es una actividad esencialmente confrontativa, y que por tanto el uso de metáforas confrontativas - tales como "ganar", "perder", "atacar" o "derrotar" - es simplemente una manera de representar lo que ocurre cuando argumentamos. Sin duda, se trata de metáforas firmemente arraigadas en nuestra cultura, pero eso no significa que sean las únicas o las mejores. En esta sección argumentaré, como ya han hecho otros, que tales metáforas confrontativas son perjudiciales para la buena práctica argumentativa $-\mathrm{o}$ al menos para nuestro ideal de la razonabilidad en la argumentación-.

Como hemos visto, varios autores han afirmado que el uso de términos confrontativos fomenta un comportamiento indeseable en la argumentación. Moulton sostuvo que el Paradigma de la confrontación fomenta la hostilidad y el comportamiento agresivo, y Cohen afirmó que la metáfora de la argumentación como una competición promueve "la astucia y la destreza retórica". No obstante, para ser justos, tales afirmaciones recibieron respuestas. Govier diferenció entre la agresividad o "confrontación adicional" y la "confrontación mínima"; y Aikin ha argumentado que las metáforas bélicas y deportivas disponen de los recursos necesarios para criticar el mal comportamiento: existen reglas incluso en las guerras y las competiciones, hay "guerras injustas", y la fuerza puede ser "desproporcionada", por ejemplo (2011, p. 257). Aunque no estoy totalmente convencido de estas respuestas, creo que tienen algo de razón. Después de todo, existen actividades confrontativas que son cualquier cosa menos agresivas - pensemos en el ajedrez o el golf-.

En cualquier caso, incluso aunque nos enfoquemos en la confrontación y dejemos a un lado la agresividad, creo que estos autores no prestan suficiente atención a la manera en que representar una actividad con ciertos términos puede fomentar determinados tipos de comportamiento y desalentar otros. Imaginemos, por ejemplo, que la práctica de la cocina fuese descrita en términos de una "carrera"; no 
debería sorprendernos que los cocineros intentaran preparar sus platos lo más rápido posible. En cambio, si la cocina se comparase con la "pintura artística", parece plausible pensar que los cocineros darían mucha menos importancia al tiempo y estarían más preocupados por el aspecto final de sus comidas, invirtiendo más esfuerzo en cada pequeño detalle. Platón, en la República (488a), usó la metáfora del comandante de un navío para describir el gobierno, y todos sabemos las implicaciones que eso tenía. Como sostuvieron Lakoff y Johnson, las metáforas "crean realidades para nosotros" y por tanto pueden ser "una guía para las acciones futuras" (1980, p. 156).

El hecho de que las decisiones de las personas están influidas por la manera en que se les presenta una situación está bien documentado en la psicología y la sociología: es el efecto marco (framing effect). Kahneman y Tversky detectaron el poder de este efecto en la década de 1980 por medio de su "problema de la enfermedad asiática"6 (Kahneman 2011, p. 368). Llevaron a cabo un experimento en el que se pidió a los participantes que eligieran entre dos opciones:

Imagine que Estados Unidos se está preparando para el brote de una inusual enfermedad asiática, que se espera que mate a 600 personas. Se han propuesto dos programas alternativos para combatir la enfermedad. Asumamos que las estimaciones científicas exactas de las consecuencias de los programas son las siguientes:

Si se adopta el programa A, se salvarán 200 personas.

Si se adopta el programa B, existe una probabilidad de un tercio de que se salven 600 personas y una probabilidad de dos tercios de que nadie se salve.

La mayoría de los participantes escogió el programa A, prefiriendo un resultado seguro a una apuesta. Entonces se realizó de nuevo el experimento con una versión ligeramente diferente del problema, en la que los efectos de los programas se formularon de la siguiente manera:

Si se adopta el programa A, morirán 400 personas.

Si se adopta el programa B, existe una probabilidad de un tercio de que nadie muera y una probabilidad de dos tercios de que mueran 600 personas.

\footnotetext{
${ }^{6}$ En mi defensa diré que cito este ejemplo en un momento como este únicamente debido a su importancia en la bibliografía de la psicología del razonamiento.
} 
Es fácil darse cuenta de que las dos versiones del problema dicen exactamente lo mismo. Sin embargo, en esta segunda versión, la gran mayoría de los participantes escogió el programa B. Esto muestra cómo la formulación de un problema influye en el comportamiento de la gente, en función de qué se enfatice. Como lo expresa Kahneman: "la mortalidad es mala, la supervivencia es buena" (p. 367).

Aunque los descubrimientos de Kahneman y Tversky sobre la presentación de cifras y porcentajes puedan dar algo de plausibilidad a la idea de que las metáforas confrontativas influyen en el comportamiento argumentativo, debe admitirse que no ofrecen pruebas claras. Sin embargo, el efecto marco también ha sido estudiado en otros contextos que no involucran diferentes presentaciones de cifras equivalentes, sino un énfasis diferente en aspectos específicos de una situación. Druckman (2001), quien ofrece un resumen de la bibliografía sobre el efecto marco, explica:

Por ejemplo, cuando un candidato enmarca una campaña en términos económicos, puede provocar que los votantes evalúen a los candidatos sobre la base de sus políticas económicas. Esto, a su vez, puede llevar a los votantes a preferir el candidato con las políticas económicas más fuertes. En cambio, si el candidato se enfoca en las políticas de asuntos exteriores, puede que los votantes hagan lo mismo y, como resultado, apoyen al candidato con las políticas de asuntos exteriores más fuertes. (p. 230)

Es más, algunas de las investigaciones que se han realizado sobre el efecto marco están relacionadas con las representaciones metafóricas. En una serie de experimentos, Robins y Mayer (2000) pusieron a prueba la hipótesis de que las metáforas influyen en la manera como las personas resuelven ciertos dilemas. En un experimento, se preguntó a los participantes si estaban de acuerdo con la aplicación de aranceles en el comercio internacional. La mitad de ellos recibieron un texto que describía el comercio en términos de una "guerra", mientras que la otra mitad recibieron un texto que lo describía con la metáfora de "una calle de doble sentido". Estos son los textos que los participantes debían leer antes de responder:

El comercio internacional es una guerra. Los aranceles o las reglas comerciales son barricadas que protegen los intereses de los países. La victoria se logra cuando un país mantiene sus propias salvaguardias pero es capaz de penetrar en los mercados de su adversario. El déficit comercial significa que estamos perdiendo terreno en el campo de batalla de 
la guerra comercial. Los aranceles nos protegerían de tales pérdidas y nos ayudarían a reclamar nuestro territorio comercial.

El comercio internacional es una calle de doble sentido. Los aranceles o las reglas comerciales son obstáculos en la carretera que impiden el flujo del tráfico comercial. El éxito en el comercio se logra eliminando todos los obstáculos de ambos lados de la calle y permitiendo el libre paso de los bienes. El déficit comercial significa que esos obstáculos están causando atascos en las carreteras del comercio. Los aranceles nos impedirían volver a alcanzar velocidad y llegar hasta nuestro destino comercial. (p. 58)

Naturalmente, los participantes que leyeron el texto de "el comercio es una guerra" estuvieron más a favor de los aranceles que los participantes que leyeron el texto de "el comercio es una calle de doble sentido". Lo mismo sucedió en otro experimento en el que los participantes tenían que dar su opinión sobre los acuerdos prematrimoniales (p. 68). Quienes leyeron una descripción basada en la metáfora "los acuerdos prematrimoniales son una red de seguridad" estuvieron a favor de los acuerdos prematrimoniales en mayor medida que quienes leyeron un texto que los describía en términos de "un arma". Es más, cuando se les pidió que justificaran sus opiniones, los participantes no mostraron ninguna señal que indicara que eran conscientes de los efectos que la metáfora había tenido en ellos.

Volvamos ahora a la concepción de la argumentación como una actividad confrontativa, una actividad con "oponentes", con "ganadores" y "perdedores". No hace falta decir que ganar es deseable y perder es indeseable. Nadie quiere perder. Perder es malo por definición. ¿Pero qué significa "perder" en la argumentación? Significa simplemente cambiar de opinión, reconocer que el otro argumentador ha presentado argumentos suficientemente buenos a favor de su punto de vista y te ha convencido. Esto es, aparentemente, lo que debe evitarse si la argumentación va sobre "ganar" y "perder". Y esto, según argumentaré a continuación, desalienta el comportamiento razonable de una manera bastante directa.

Como sabe cualquier filósofo, el término "razonable" puede tener una amplia variedad de significados — desde la concepción pragmadialéctica de la razonabilidad en la argumentación hasta la idea de razonabilidad en la filosofía política de Rawls-. Sin embargo, me gustaría centrarme en un aspecto concreto que tiene que ver específicamente con la argumentación, uno que (según creo) surge a partir de un análisis del uso real que hacen los hablantes del término "razonable". El aspecto de la razonabilidad que tengo en mente se manifiesta 
en expresiones que los hablantes ordinarios - todos nosotros - usan en contextos argumentativos, tales como:

Puedes hablar con ella, es muy razonable.

¡Vamos, sé razonable!

Estoy intentando ser razonable.

¿Qué nos sugieren estas expresiones sobre el término "razonable"? Me parece que, cuando le pedimos a alguien que sea razonable en el contexto de una discusión argumentativa, la situación suele ser una en la que a esa persona se le han ofrecido buenos argumentos que ella se niega a considerar seriamente. ${ }^{7}$ Se ha visto que hay razones para que esa persona considere la posibilidad de que está equivocada, pero ella las está ignorando. En ese sentido, esa persona está siendo poco razonable. Del mismo modo, cuando decimos de una persona que "puedes hablar con ella" porque es "razonable", normalmente queremos decir que tal persona está dispuesta a escuchar tus razones, a comprenderlas y posiblemente a cambiar de opinión. Y, finalmente, si alguien dice que está "intentando ser razonable", esa persona supuestamente está tratando de tener en cuenta todas las razones que ha escuchado y de considerar las creencias y los intereses de todos los involucrados en la discusión. Lo que sugieren estos ejemplos, en mi opinión, es que decir que alguien es razonable implica atribuirle una disposición a modificar sus creencias sobre la base de buenas razones.

En cierto sentido, la teoría pragmadialéctica de la argumentación, en la que el concepto de razonabilidad ocupa un lugar central, podría proporcionar una base para esta interpretación. La concepción pragmadialéctica de la razonabilidad se refleja, por supuesto, en las conocidas reglas de la discusión crítica (Eemeren 2018). Sin embargo, esas reglas están inspiradas en una concepción filosófica de la razonabilidad. Siguiendo la distinción de Toulmin entre una concepción geométrica, una concepción antropológica y una concepción crítica de la razonabilidad, los pragmadialécticos adoptan la concepción crítica —o, siendo más precisos, una adaptación de la misma, que denominan racionalismo crítico- - Esta concepción racionalista crítica

${ }^{7}$ Buenos argumentos, por supuesto, según quienes decimos eso. Puede que los argumentos sean realmente malos o (más probablemente) que nuestro oyente considere que son malos. No obstante, el hecho que nos interesa aquí es que, cuando decimos eso, consideramos que el oyente no está prestando la atención debida a buenos argumentos. Agradezco a Raymundo Morado que llamara mi atención sobre este punto. 
"parte de la sospecha de que no podemos estar seguros de nada, de tal modo que debemos ser escépticos frente a cualquier afirmación, quienquiera que sea quien la haga y cualquiera que sea su ámbito" (Eemeren 2015, p. 88). En una extensa discusión sobre el concepto de razonabilidad, Eemeren y Grootendorst destacaron el reconocimiento crítico-racionalista de la posibilidad omnipresente de estar equivocado:

¿Qué implica la sustitución de la razonabilidad geométrica y la antropológica por la razonabilidad crítica? Si se adopta el punto de vista de un racionalista crítico popperiano, se busca el desarrollo de un modelo de razonabilidad que tiene explícitamente en cuenta la falibilidad de la razón humana, y eleva el concepto de examen crítico sistemático en todas las áreas del pensamiento y la acción humanos a la categoría de principio orientador de solución de problemas. (1988, p. 279)

Por supuesto, no pretendo sostener aquí que ser razonable consista meramente en estar dispuesto a cambiar de opinión ante buenos argumentos. El concepto de razonabilidad es muy amplio y dudo mucho que pueda caracterizarse completamente por medio de una única condición. Y, desde luego, tampoco se puede esperar de las personas razonables que abandonen sus creencias ante cualquier argumento, por débil que sea. Lo único que estoy afirmando aquí es que ser razonable implica desear llegar hasta la verdad y por lo tanto ser relativamente indiferente a la cuestión de si las creencias propias deben modificarse o no. Como ya expliqué, la disposición a cambiar de opinión puede entenderse de esta manera; únicamente excluye querer conservar las creencias propias, lo que llevaría a una reticencia a cambiar de opinión.

Esta disposición a cambiar de opinión, sin embargo, no debe entenderse de una manera demasiado ingenua. $\mathrm{Al}$ comentar los argumentos de Casey se admitió su premisa de que las creencias son involuntarias, así que tal disposición no puede referirse al modo en que deberíamos manejar directamente nuestro sistema de creencias. Se refiere al tipo de circunstancias a las que deberíamos estar dispuestos a exponernos y que pueden tener un efecto causal en nuestras creencias. Por ejemplo: debemos escuchar argumentos en contra de nuestras creencias, prestarles atención, comprometernos a seguir procedimientos racionales de discusión y cultivar las virtudes argumentativas (Cohen 2019). Aunque no tengamos un control directo sobre nuestras creencias, sin duda nuestra exposición a factores causales como esos depende de nuestra voluntad. 
De nuevo, como ya indiqué en la sección 3, admito que existen ciertos contextos en los que los argumentadores no deberían estar dispuestos a cambiar de opinión. Los abogados y los políticos, en particular, probablemente no deberían desarrollar el hábito de decir: "¿Saben qué? ¡Creo que mi interlocutor tiene razón!” Eso, sin embargo, tiene más que ver con el aspecto pragmático de los compromisos que con las creencias. Sin duda, los compromisos públicos involucran todo tipo de consideraciones pragmáticas y sociales. Aquí, sin embargo, en la misma línea que Casey, me estoy centrando en las creencias, que tienen que ver con consideraciones epistémicas. En general, los compromisos deberían corresponderse con las creencias, pero admito que ciertas actividades sociales exigen una separación de ambas.

Si mis argumentos en esta sección son plausibles, entonces la conclusión es obvia: el paradigma de la confrontación y el ideal de la razonabilidad transmiten mensajes incoherentes entre sí. Al describir la argumentación en términos confrontativos, se insta a los participantes a que eviten "perder" — es decir, cambiar sus creencias-. Al elogiar la razonabilidad, se anima a los participantes a que estén dispuestos a modificar sus creencias si resultan estar equivocadas. Uno de los dos debe rechazarse.

\section{Por qué importa la razonabilidad}

$\mathrm{Si}$, llegados a este punto, he conseguido convencer a alguien de que la confrontación no es esencial a la argumentación y de que debemos elegir entre la confrontación y la razonabilidad, entonces no creo que esta sea una elección muy difícil. El siguiente paso de mi argumentación — que la razonabilidad debe promoverse en la argumentación - será, espero, relativamente poco controvertido. La conclusión final, por supuesto, será que debemos deshacernos del paradigma de la confrontación. En cualquier caso, probablemente sea oportuno hacer unos pocos comentarios sobre el valor de la razonabilidad, y ese es el objetivo de la presente sección.

Por motivos de espacio, aquí solo esbozaré dos argumentos en favor de la razonabilidad. En primer lugar, al participar en una discusión argumentativa con la disposición de modificar las creencias propias de acuerdo con las mejores razones, el resultado del intercambio probablemente sea la obtención de creencias más fiables - y, en el caso de la argumentación práctica, mejores decisiones-. En la medida en que los argumentadores estén interesados en la corrección de sus propias creencias, ese no será simplemente un objetivo de la 
actividad colectiva sino que también será beneficioso para cada uno de ellos. En segundo lugar, en contra de la tesis de Casey, creo que las personas que critican nuestras creencias y nos convencen de algo con buenas razones realmente nos están ayudando a tomar control de nuestro sistema de creencias. Veamos estos dos argumentos por orden.

Muchos investigadores han señalado que la argumentación conduce a conclusiones de mejor calidad que las del razonamiento solitario. La teoría argumentativa del razonamiento, desarrollada por Mercier y Sperber (2017), se basa en gran medida en este hecho; según esta teoría, la principal función de la razón humana es producir y evaluar argumentos, y es en contextos argumentativos donde la razón funciona mejor. Mercier (2016) revisa varios estudios empíricos que muestran que el rendimiento de las personas mejora cuando abordan varias cuestiones en discusiones grupales, en lugar de por medio del razonamiento solitario.

Los beneficios de la argumentación, naturalmente, provienen del hecho de que los buenos argumentos influyen en las creencias durante las discusiones. Es muy improbable que detectemos fallos en nuestras razones cuando razonamos por nuestra cuenta, pero la argumentación proporciona un ambiente en el que nuestras razones pueden ser evaluadas de manera más adecuada. La argumentación es una oportunidad, no una amenaza, y los argumentadores razonables lo ven de esa manera. Como explican Mercier y Sperber: "Cuando las personas razonan por su cuenta, producen principalmente razones que apoyan sus decisiones o sus ideas preconcebidas, y no se molestan en asegurarse de que sus razones son fuertes" (2017, p. 235).

Esto es resultado del sesgo de confirmación o sesgo de mi lado (myside bias), la tendencia a encontrar en mayor medida argumentos que apoyan los puntos de vista propios, que estos autores consideran como un rasgo inherente a la razón humana. Sin embargo, es importante señalar aquí que, aunque el sesgo de mi lado también está presente en contextos argumentativos, este hecho por sí solo no implica que las discusiones deban ser confrontativas. Una cosa es decir que estamos sesgados hacia nuestros propios puntos de vista, y otra cosa diferente es decir que somos reacios a abandonarlos - lo primero tiene que ver con el funcionamiento de la razón y lo segundo con nuestras motivaciones-. Como indican Mercier y Sperber: "El sesgo de mi lado no convierte la argumentación en una actividad puramente competitiva. La argumentación es una forma de comunicación y típicamente se desarrolla de manera cooperativa" (p. 221). 
Cuando los argumentadores no ven la argumentación como una oportunidad para su propia mejora, tienden a ser poco razonables - reacios a permitir que sus creencias se vean afectadas pase lo que pase - Los contextos confrontativos, en los que lo que está en juego es ganar o perder, proporcionan incentivos para proteger las creencias previas, en lugar de incentivos para llegar a mejores creencias. La investigación en psicología ha mostrado que esta preferencia por ciertas creencias en lugar de por la corrección epistémica suele distorsionar nuestro razonamiento. Kunda (1999, p. 212) llamó metas de dirección (directional goals) a esas preferencias por una creencia en particular y presentó pruebas empíricas de que tales metas pueden sesgar nuestros razonamientos. En cambio, las metas de corrección (accuracy goals), la motivación de llegar a las creencias más correctas (sean cuales sean), llevan a las personas a invertir un mayor esfuerzo y a buscar las mejores estrategias de razonamiento (p. 235). La razonabilidad, tal como ha sido caracterizada aquí, implica la adopción de metas de corrección.

Mi segundo argumento en favor de la razonabilidad tal vez sea más especulativo pero está igualmente basado en investigaciones empíricas: creo que, cuando modificamos nuestras creencias a la luz de buenos argumentos que otra persona ha presentado, nuestro control sobre nuestras creencias realmente aumenta. Por paradójico que pueda parecer, cuando otras personas nos convencen de algo con buenos argumentos, eso nos hace comprender mejor nuestras creencias y su procedencia. Para ver por qué, empecemos por preguntarnos: ¿cómo se formaron nuestras creencias previas - anteriores a la argumentación - ? La respuesta es simplemente que, en gran medida, no lo sabemos. Se trata de creencias intuitivas, en el sentido de Mercier y Sperber: creencias producidas por procesos inferenciales de los que no somos conscientes (2017, p. 66). Puede ser que las tengamos simplemente porque las hemos obtenido de otras personas, como afirma Kahneman: "Para algunas de nuestras creencias más importantes no tenemos absolutamente ninguna prueba, excepto el hecho de que hay personas a las que amamos y en las que confiamos que tienen esas creencias" (2011, p. 209).

Sin duda, puede que hayamos reflexionado sobre al menos algunas de esas creencias. No obstante, incluso tras el razonamiento solitario, el origen de tales creencias es confuso. Nisbett y Wilson (1977) realizaron una serie de experimentos que demostraron que somos muy poco fiables cuando intentamos responder a la pregunta de por qué razones tomamos cierta decisión. Ciertamente, proporcionamos razones, a menudo con mucha convicción, pero con demasiada frecuencia 
las razones que damos son incorrectas - no son esas razones las que causaron nuestra decisión-.

En cambio, cuando alguien cambia de opinión tras un intercambio de argumentos, hay pocas dudas sobre qué fue lo que causó tal cambio. Los buenos resultados que produce la deliberación grupal favorecen la hipótesis de que los argumentos fueron la causa. Estudios empíricos han excluido otros factores, tales como la seguridad con la que hablan los argumentadores (Trouche et al. 2014). Es más, parece que la deliberación permite que las personas se liberen de las distorsiones causadas por mensajes manipuladores y que adopten creencias que son más acordes con sus auténticos intereses (Niemeyer 2011). Así que, en un sentido muy real, los argumentadores que nos convencen nos están ayudando a comprender y controlar nuestras propias creencias.

Ser razonable consiste, en parte, en comprender que la argumentación y la modificación de nuestras creencias sobre la base de buenas razones son beneficiosas para nosotros mismos en ese sentido. Quien, en lugar de participar en una discusión con una actitud razonable, la ve como una competición y actúa en consecuencia, probablemente prestará menos atención a las razones de su interlocutor y será más reacio a cambiar de opinión incluso ante buenas razones - como se argumentó en la sección anterior-. Por lo tanto, será menos probable que obtenga ese beneficio de la argumentación: en lugar de tomar un mayor control sobre su sistema de creencias, se aferrará a sus creencias intuitivas previas, de orígenes inciertos.

\section{Conclusión}

En resumen, he sostenido que la argumentación no es una actividad esencialmente confrontativa, ya que ni el desacuerdo ni la involuntariedad de la creencia implican necesariamente una confrontación. Para que una actividad sea confrontativa, como mínimo los participantes deben tratar de imponer a otros un resultado que estos últimos sean reacios a aceptar — de modo que tenga sentido decir que unos ganan y el otro pierde-. Por tanto, la argumentación solo será confrontativa en la medida en que los participantes sean reacios a modificar sus creencias a la luz de buenas razones.

A continuación, he argumentado que la metáfora de la argumentación como una competición —o, peor, como una guerra- fomenta precisamente esa reticencia en los argumentadores, y eso entra en conflicto con un ideal de la razonabilidad según el cual los argumentadores razonables son aquellos que están dispuestos a modificar 
sus creencias cuando sea necesario. Esto, en mi opinión, nos da una buena razón para sospechar de las metáforas confrontativas. La razonabilidad es un ideal que debe ser protegido, ya que promueve una de las metas más valiosas de la argumentación - llegar a mejores creencias y decisiones - y aumenta nuestro control sobre nuestro propio sistema de creencias.

Nótese que nada de lo que he dicho aquí tiene que ver con la agresividad — que, como señalaba Govier, debe distinguirse de la confrontación-. El principal problema no es que la confrontación pueda llevar a la hostilidad y la rudeza; el problema es la confrontación misma. Establece unos objetivos para los argumentadores que entran en conflicto con los objetivos de la argumentación razonable. $\mathrm{Si}$, en la práctica, un gran número de discusiones argumentativas se perciben como una confrontación, eso no es sino un rasgo accidental de nuestras sociedades actuales que puede y debe extirparse de nuestras prácticas argumentativas. ${ }^{8}$

\section{BIBLIOGRAFÍA}

Aikin, S., 2011, "A Defense of War and Sport Metaphors in Argument", Philosophy and Rhetoric, vol. 44, no. 3, pp. 250-272.

Brockriede, W., 1972, "Arguers as Lovers", Philosophy and Rhetoric, vol. 5, no. 1, pp. 1-11.

Casey, J., 2020, "Adversariality and Argumentation", Informal Logic, vol. 40, no. 1, pp. 77-108.

Cohen, D.H., 2019, “Argumentative Virtues as Conduits for Reason's Causal Efficacy: Why the Practice of Giving Reasons Requires that We Practice Hearing Reasons", Topoi, vol. 38, pp. 711-718.

— , 1995, "Argument Is War... And War Is Hell: Philosophy, Education, and Metaphors for Argumentation", Informal Logic, vol. 17, no. 2, pp. 177-188.

Druckman, J.N., 2001, "The Implications of Framing Effects for Citizen Competence", Political Behavior, vol. 23, no. 3, pp. 225-256.

Eemeren, F.H. van, 2018, Argumentation Theory: A Pragma-Dialectical Perspective, Springer, Dordrecht.

— 2015, Reasonableness and Effectiveness in Argumentative Discourse, Springer, Dordrecht.

${ }^{8}$ Una versión anterior de este artículo se presentó en el III Coloquio de Argumentación y Retórica, celebrado los días 7-11 de diciembre de 2020 en la Universidad Autónoma de Nayarit (México). Agradezco los comentarios de Mario Gensollen, Raymundo Morado, Fernando Leal, Daniel Mejía y otros asistentes, que me sirvieron para mejorar varios puntos del artículo. Este trabajo se enmarca en el proyecto FONDECYT ANID/CONICYT de Postdoctorado n. 3190149 del gobierno de Chile. 
Eemeren, F.H. van y R. Grootendorst, 1988, "Rationale for A PragmaDialectical Perspective", Argumentation, vol. 2, no. 1, pp. 271-291.

Govier, T., 1999, The Philosophy of Argument, Vale Press, Newport News, VA.

Harding, S. y M.B. Hintikka (eds.), 1983, Discovering Reality: Feminist Perspectives on Epistemology, Metaphysics, Methodology, and Philosophy of Science, Kluwer Academic Publishers, Dordrecht.

Kahneman, D., 2011, Thinking, Fast and Slow, Farrar, Straus and Giroux, Nueva York.

Kunda, Z., 1999, Social Cognition: Making Sense of People, MIT Press, Cambridge, MA.

Lakoff, G. y M. Johnson, 1980, Metaphors We Live By, University of Chicago Press, Chicago.

Mercier, H., 2016, "The Argumentative Theory: Predictions And Empirical Evidence", Trends in Cognitive Sciences, vol. 20, no. 9, pp. 689-700.

Mercier, H. y D. Sperber, 2017, The Enigma of Reason, Harvard University Press, Cambridge, MA.

Moulton, J., 1983, "A Paradigm of Philosophy: The Adversary Method", en Harding y Hintikka 1983, pp. 149-164.

Niemeyer, S., 2011, “The Emancipatory Effect of Deliberation: Empirical Lessons from Mini-Public", Politics \& Society, vol. 39, no. 1, pp. 103140.

Nisbett, R.E. y T.D. Wilson, 1977, "Telling More Than We Can Know: Verbal Reports on Mental Processes", Psychological Review, vol. 84, no. 3, pp. 231-259.

O'Keefe, D.J., 1977, "Two Concepts of Argument", The Journal of the American Forensic Association, vol. 13, no. 3, pp. 121-128.

Robins, S. y R.E. Mayer, 2000, "The Metaphor Framing Effect: Metaphorical Reasoning about Text-Based Dilemmas", Discourse Processes, vol. 30, no. 1, pp. 57-86.

Rooney, P., 2010, "Philosophy, Adversarial Argumentation, and Embattled Reason", Informal Logic, vol. 30, no. 3, pp. 203-234.

Trouche, E., E. Sander y H. Mercier, 2014, "Arguments, More Than Confidence, Explain The Good Performance of Reasoning Groups", Journal of Experimental Psychology: General, vol. 143, no. 5, pp. 19581971.

Recibido el 10 de diciembre de 2020; aceptado el 24 de enero de 2021. 